\title{
Gender disparities and positioning in collaborative hospitality and tourism research
}

\begin{abstract}
Purpose: To explore gender disparities in the production of tourism knowledge with particular reference to academic journals.
\end{abstract}

Design/methodology/approach: Authorship and co-authorship analyses were conducted of data extracted from articles and research notes published between 1965 and 2016 in 25 hospitality and tourism journals.

Findings: Gender imbalances are evident in the production of knowledge, though the disparities appear to be decreasing. While heterophilic research collaborations (those between men and women) show some evidence of higher productivity, homophilic collaborations (between males) have greater impact. The findings highlight gender imbalances in international collaborations, in SSCI listed journals, in first authoring, and by country. There is evidence of higher collaborative levels amongst male authors and the differences have increased over time. The positioning of men and women within tourism scholarly networks shows no marked differences.

Practical Implications: This data-driven analysis provides decision-makers and policymakers with evidence to support well targeted programs that advance female contributions in hospitality and tourism research collaborations. For example, senior academics and University administrators might offer support for female researchers to become more actively involved in hospitality and tourism research groups and projects. Universities or schools might also seek to encourage collaborations between male and female researchers in their performance indicators. Originality/Value: This study is one of the first to examine gender disparities and positioning in collaborative hospitality and tourism research.

Keywords: gender, collaboration, equality, homophily, SSCI 


\section{Introduction}

This study explores the evolution of research collaboration networks in the hospitality and tourism literature based on gender. Many previous studies have described the authorship and coauthorship structures that are prevalent in hospitality and tourism (Benckendorff, 2010; Hu and Racherla, 2008; Ye et al., 2013; Ye et al., 2012). However, only one study has addressed authorship structure in the context of gender (Nunkoo et al., 2017). Drawing upon author contributions to Annual of Tourism Research, the investigation noted an increase in the proportion of female authorships, and that women authored more papers using qualitative research methods. Despite such valuable insights, previous related studies have drawn upon limited sample sizes and time spans, and gender has been deployed primarily to examine either the maturity and/or the sophistication of collaborations. If researchers, practitioners, and policy makers are to design policies that provide better motivation for scholars to collaborate effectively, they will need a stronger evidential base on the role of gender in networks. The present study addresses the gap by exploring and evaluating the growth and evolution of collaboration structures based on gender, with a view to understanding the maturity level of hospitality and tourism research through a) evaluating authorship structures in hospitality and tourism research by gender over time, b) examining national and international collaborations by gender, c) determining gender-based productivity in the leading journals, d) highlighting co-authorship network positioning by gender and e) presenting a visualization of gender-based co-authorship networks over time.

Twenty-five leading hospitality and tourism journals were selected for review. These publications had the highest impact factors at the time of evaluation (Impact Factor- Journal of Citation Report and SCR-Scopus) or were most recognised by scholars (Gursoy and Sandstrom, 2016). The present study addresses gender structures within the network with a view to 
(re)formulating enhanced policies for research collaboration. To this end, the researchers employed a co-authorship analysis approach (Dehdarirad and Nasini, 2017). The paper is structured as follows. First, the authors present a literature review on research collaborations and gender. The second section outlines the chosen research method. This is followed by findings and limitations, opportunities for future research and finally conclusions.

\section{Literature Review}

\section{Gender within Academia}

The pursuit of gender equity in research is worthwhile on philosophical grounds and also because enhanced female participation can address current and future demands for skilled labour. Women are currently and historically under-represented in research across both the public and private sectors (She Figures, 2012). In higher education, where the numbers of women who are graduating outnumber their male counterparts, only ten percent of university rectors/presidents/ vice-chancellors are women (She Figures, 2012). When the gender gap and positioning structures at research institutions are considered, a 'pipeline-structure' is evident that governs the path from Ph.D. student to professor (Saunders, 2002). The leaky pipeline is a frequently used metaphor to describe the fact that women are under-represented in academia (Blickenstaff, 2005). It conveys the idea that the proportion of women differs from one level to the next and assumes that the pipeline "leaks", as female scholars leave the pipeline at various stages of their careers. For example, female researchers are still the subject of gender bias when it comes to passing the $\mathrm{CV}$ assessment stage during recruitment (Kassabian and Zur, 2014). Research conducted in Spain has shown that men are 2.5 times more likely than women within the same subject area to be promoted from associate to full professor, controlling for other personal, familial and professional characteristics (including research productivity) (UMYC, 2011). 
The inequity extends to remuneration and there is an ongoing gender-based pay gap. Female scientists in the public sector within the European Union earned on average between 25\% and 40\% less than males in 2006 (O'Dorchai et al., 2009). Further, ambiguity is still commonplace at the decision-making level about recognising the skills and competencies of women researchers (Leung and Law, 2006). In practice, a great deal of evidence suggests that women's scientific efforts and achievements are less recognized than those of men. This phenomenon has been described as the 'Matilda Effect' (Knobloch-Westerwick et al., 2013). A number of studies have found evidence of how this state of affairs produces bias against female scholars. For example, female scholars receive fewer citations (Knobloch-Westerwick and Glynn, 2013), less scientific awards and smaller grant funding relative to their male colleagues (Bornmann et al., 2007; RAND, 2005). It has been shown that men are eight times more likely to win a scholarly award compared to women and almost three times more likely to win a young investigator award (Lincoln et al., 2012).

Researchers in the USA have shown that family formation (marriage, childbirth) has a disproportionally larger effect on the careers of women than of men. When considered alongside the under-development of family-friendly policies within universities, this accounts for the 'talent leak' between graduation and academic employment (Goulden et al., 2011). Studies and statistical reports have shown that women are also under-represented as knowledge leaders in the global academy. Such under-representation has been persistent over time and across leadership categories (Husu, 2013). Although overtly discriminatory practices such as separate staff common rooms no longer prevail, a complex range of hidden barriers remains in the shape of stereotypes and organisational practices that have a negative or skewing effect on the career paths of women scholars (Zoghbi and Greengard, 2014). The metaphor of a glass labyrinth (Smith et al., 2012), 
describes the maze of individual, organisational and wider social barriers that women researchers must navigate through the course of their careers. Hence it may be observed that gender patterns in higher education institutions remain largely unchanged internationally, despite national and institutional policies and initiatives to address gender (in)equalities. It is evident that no country in the world has achieved an entire closing of the gender gap across health, education, employment or politics (World Economic Forum, 2016).

A major focus of gender research concerns the roles, careers and representation of women in academia (Bagilhole and White, 2013) and hospitality and tourism scholars have devoted considerable attention to these topics (Munar, 2017; Jeffrey, 2017; Ek and Larson, 2017; Pritchard et al., 2007; Swain and Momsen, 2002). The report "Gender Gap in the Tourism Academy" (Munar et al., 2015) concluded that women are under-represented in senior leadership positions in tourism academia, and that there is an imbalance in the number and influence of women compared with men. Pritchard and Morgan (2017) examined gender and performance and identified gender inequalities on the editorial boards of 12 leading tourism journals, in the tourism professoriate of three countries (UK, Australia, and New Zealand) and in relation to the citation metrics for tourism scholars.

\section{Gender in the Production and Dissemination of Knowledge}

The publication and citation of scholarly work is frequently used as an indicator of scholarly visibility and of research quality and impact (Ward et al., 1992). The dictum "publish or perish" is commonly used to characterize the importance of publishing and reflects the challenge confronting academics around the world - the urgency to publish (L'Huillier, 2012). However, studies of citation patterns have raised questions about whether women's scholarly outputs are published and cited as frequently in academic journals as those of men and whether there are 
gender disparities in scholarly collaborations (Zoghbi and Greengard, 2014; Smith et al., 2012).

There appear to be more collaborations between female and female or male and male authors (homophily) and fewer between male and female authors (heterophily) (Badar et al., 2016). To subject this proposition to further scrutiny, the current authors proceed to use homophily and heterophily theory in order to identify the nature of collaborations in the hospitality and tourism field. Whilst the former emphasizes that people are "more likely to interact with individuals similar to themselves in respect to a variety of qualities and characteristics" (Yuan and Gay, 2006, p. 1063), the latter concerns the greater likelihood of interactions between those that are more differentiated.

\section{Overview of Previous Studies}

The subject of gender and of particularly of gender differences has been of interest across all societies that are seeking balanced contributions to organizations and systems. A large number of studies (Figueroa-Domecq et al., 2015; Perryman et al., 2016) have been conducted on aspects of gender and on gender differences. Several have examined gender in the context of authorship and co-authorship structures in research collaborations. Bozeman and Corley (2004) observed that female academics have less cosmopolitan networks. Badar et al.'s (2013) study of female chemistry researchers in Pakistan concluded that research collaborations contribute to enhanced productivity. Abramo et al., (2013) found that Italian female researchers engaged in domestic collaborations both within and beyond their institutions, though to a lesser extent internationally than their male counterparts.

Scharber et al., (2019) illustrated notable differences in the publication rates between genders for articles published in education technology journals between 2004 and 2015. They found that female researchers published fewer than half of the articles in the relevant publications. 
As was noted previously, Nunkoo et al., (2017) investigated methodological choice and gender in the case of papers published in Annals of Tourism Research between 1990 and 2015. Although the proportion of female authors of articles increased from $19 \%$ in 1990 to $49 \%$ in 2015 , they noted that males remained as leader. They also observed that female researchers have a greater propensity to adopt qualitative approaches. Recently, Ghiasi et al., (2018) identified gender inequality and collaboration patterns in Canadian nanotechnology research. They found that papers with female first authors have a lower citation rate than those with male first authors. A study by Gallardo-Gallardo et al., (2017) addressed the respective positions of males and females in collaboration networks related to talent management research. The foci of the present study are quite distinct from the coverage of previous hospitality and tourism studies by emphasizing:

- How networks have evolved from the perspective of gender;

- authorship and collaboration structures based on gender;

- a larger sample and better representation of the field through the inclusion of more journals (25); and

- a more extended time frame (1960-2016).

\section{Methodology}

\section{Authorship and co-authorship analyses via social network analysis.}

Authorship and co-authorship analyses form part of the wider phenomenon of bibliometric analysis, a method that helps researchers to understand the state of the art in a given field. While authorship analysis deals with the author structures in the published outputs, co-authorship analysis identifies the social structure of a given field. Basic equations are used as suitable evaluative methods in the conduct of authorship analyses. However, relational methods are necessary in the case of co-authorship analysis and involve the deployment of approaches such as factor analyses, 
multidimensional scales, and network analyses (Zupic and Čater, 2015, p. 439). The present study relies on a commonly used technique for the analysis of co-authorships - social network analysis (Munoz et al., 2016). The social network analysis method is used here to evaluate relationship networks by mapping and analysing the relationships amongst individuals, groups, departments, and institutions. The social network analysis approach allows researchers to investigate communication and collaborative mechanisms between members of scientific groupings (Serrat, 2017, p. 41). Co-authorship network analysis shows how actors or authors are interconnected by displaying their collaborative outputs (Benckendorff, 2010). Researchers can identify the strength of ties within a network and the positioning of authors within a given community (Koseoglu, 2016a).

\section{Compilation of Bibliometric Data}

Selection of database and journals. For analysis purposes, the present authors consider hospitality and tourism focused journals indexed in the Social Science Citation Index and Google Scholar's journal metrics (h5-index). These journals were chosen primarily because of their status as leaders in the field, based on their impact factors (Impact Factor- Journal of Citation Report and SCR-Scopus) or because they are the most reputed amongst researchers (Gursoy and Sandstrom, 2016). The selected journals and the scope of the proposed dataset are presented in Table 1.

Insert table 1 about here

Extracting the articles. The researchers considered full-length articles and research notes as representative of the full range of journal outputs. The latter extends to articles, research notes, 
letters, opinions and views. The designated inclusions were confined to articles and research notes since there is widespread acknowledgment that these constitute a type of certified knowledge (Ramos-Rodríguez and Ruíz-Navarro, 2004). This is because peer-review processes apply to the publication of both articles and research notes. Second, the authors highlight the period of coverage. The study was comprehensive to the end of 2016 which was chosen as the cut-off and no other time restrictions were imposed. All issues of the selected journals were considered. As can be seen in Table 1,21,818 articles were extracted.

Exporting bibliometric data. When conducting authorship and co-authorship analyses it is necessary to identify the names and affiliations of the authors that are associated with the outputs. In the present study a research assistant undertook manual exporting of the author names and affiliations from all downloaded articles into an Excel spreadsheet.

\section{Analysis}

In the following section the researchers explain the data cleaning, the methods to identify the evolution of authorship structures and research collaborations based on gender, and the choice of bibliometric software (BibExcel, Sitkis, SciMat). For the purposes of data cleaning, the researchers conducted a frequency analysis to identify authors with the same names or initials, to detect any misspellings during the insertion phase, and to check for spelling differences between author names or combinations of author names (eg. different or variable initials (Kumar and Jan, 2013). Finally, the researchers undertook a network analysis pilot test covering all articles to enhance the validity and reliability of the study. This approach was consistent with previous studies (Koseoglu, 2016a). Any errors that were identified in the network, such as misspellings, and duplication of author names were manually corrected in the data file. Given the potential for inconsistencies in the transcription of such a magnitude of articles, the researchers applied a cut- 
off point that would contribute to explaining the gender-based evolution of authorships and coauthorships in hospitality and tourism (Leung et al., 2017; García-Lillo et al., 2016). This prompted the researchers to retrieve authors from the database who had contributed at least ten coauthored articles. To identify the relevant authorships, the researchers conducted a frequency analysis for all of the applicable articles before extracting the author outputs (8,751 papers) from the dataset $(21,818)$. Table 1 presents the frequency and percentage of these articles across the complete database of 25 journals by journal. They represent $40.07 \%$ of the original database. The ensuing analysis included all of the authors who had contributed to the selected papers $(8,751$ papers). Google and/or Researchgate were used to identify the genders of authors in the new database and a corresponding code was assigned.

A network analysis approach was used because of its capacity to identify the position of actors within the community or field. BibExcel was chosen as the applicable bibliometric software since it automatically prepares data for network analysis by considering co-occurrence among citations (Úbeda-García and Marco-Lajara, 2016). As is presented in Figure 1, the authors adopted six sub-periods to demonstrate the evolution of the field (before 1992, 1992-1996, 1997-2001, 2002-2006, 2007-2011, and 2012-2016) based on the distribution of publications by year. The selected periods allowed for the identification of publication patterns and trends. As noted by Ramos-Rodríguez and Ruíz-Navarro (2004), this approach is preferable to logging on the basis of periods of particular significance.

Insert figure 1 about here

\section{Visualization}


In the present study the authors deployed network analysis to visualize the relationships among authors and co-authorship analysis via network visualizations and analyses to calculate related metrics by using the Gephi network analysis software package.

\section{Findings and Opportunities for Future Research \\ Gender Representations in Collaborative Articles}

Collaborations play a critical role in the creation and dissemination of research knowledge. The quality of articles and intellectual contribution that they make is enhanced by collaboration (Galegher et al., 2014). It is worth considering the nature of such collaborations, especially in the case of gender, given its influence on the formation of human and social capital (Buchan et al., 2016). Previous discussions have focused on the representation and position of gender in collaborations (Rhoten and Pfirman, 2007). It has previously been noted that gender disparities persist, though the incidence of female authors in scientific articles has been increasing (West et al., 2013). Various studies of gender-based disparities in collaborative articles by productive authors in hospitality and tourism (see Table 2), have found that the percentage of contributions (i.e., appearances by author) of female authors (20.72\%) in the first period (prior to 1992) was less than for male authors (79.28\%). The disparity decreased marginally into the final period. The overall contribution of females was $33.67 \%$ versus $66.33 \%$ for males. Additionally, a change has been noted over time in the percentage of female and male authors who contributed on a single occasion. The percentage of female authors who contributed to collaborative articles only once, increased from $22.62 \%$ to $45.28 \%$, while the percentage for male authors decreased slightly from $77.38 \%$ to $54.72 \%$. The "leaky pipeline" analogy, which has been evident in other disciplines may be to explain this change. This is the process by which "women disproportionately leave academia after graduate or postdoctoral training" (West et al., 2013, p. e66212). 
The current study shows that the disparity between the percentage of female and male authors decreased from around $53 \%$ in the first period (from $76.24 \%$ to $23.76 \%$ ) to around $13 \%$ in the last period $(56.44 \%$ to $43.56 \%)$. However, it should be noted that there have been observable changes in these percentages since 2007 . The results for the hospitality and tourism domain show that whilst gender disparities have decreased in the representation of authors in collaborative articles, disparities persist in the case of author contributions for the articles (Table 2). The findings show that female representation in academic journals has improved (as was previously noted by Nunkoo et al., (2017)). However, there are still significant gender disparities in academic publications. This may be attributable to the effects of social and human capital on gender in society, to workplace cultures within research teams and to the acquisition of credit and recognition, reflective of the Matilda effect (Rossiter, 1993).

Insert table 2 about here

\section{Authorship Sequencing}

Two alternative approaches are commonly used for the sequencing of authorships within articles: alphabetical ordering, which is commonplace in mathematics, economics, and high energy physics; and contribution-based ordering (Ghiasi et al., 2018; Waltman, 2012). Recent studies (Clement, 2014; Waltman, 2012; West et al., 2013) have shown a significant decline in the incidence of alphabetical ordering and that contribution-based ordering is now widely practiced across many fields. West et al. (2013) highlighted the prestige that is attached to first authorships in contribution-based ordering, since position is considered during the processes of hiring and promotion. Similarly, last authors occupy prestigious positions in contribution-based ordering, 
since the last author position is often occupied by high-ranking, principal researchers. The previous section suggests that examining gender to understand sequencing may reveal gender disparities (Ghiasi et al., 2018). Using a comprehensive sample and significant timespan, West et al. (2013) demonstrated that males are dominant in author positioning, even though the raw publication counts by gender seem relatively equal. Other studies of the medical literature (Dotson, 2011; Jagsi et al., 2006), found that female authors have been underrepresented in the prominent positions. Although gender disparities between first authorship have declined in the medical literature, female last authors remain underrepresented.

Figure 2 presents the evolution of gender disparities across hospitality and tourism in the first and last authorship positions. Disparities are substantial for the first and last author positions during the first period $-54.78 \%$ and $52.21 \%$ respectively. However, it appears that the disparities have declined over time in the case of hospitality and tourism articles (Figure 2). Consistent with the findings of the previously mentioned studies, the disparity in first author positioning during the last period has substantially reduced (to 5.46\%). However, the equivalent for the final author position remains large (20.71\%) and has changed little over the last two periods. This may reflect a tendency for male principal researchers and supervisors to play a disproportionate role in the world of hospitality and tourism academic journals and for the persistence of the habit of including their names in the list of contributors.

Insert figure 2 about here

Productivity by Country/Region 
Many countries and regions have implemented policies to minimize academic gender inequities. Ghiasi et al. (2018) showed how Canadian initiatives increased female participation in the scholarly research environment. In their global and cross-disciplinary bibliometric analysis, Larivière et al., (2013) identified greater gender parity in the case of countries in South America and Eastern Europe. The position of Eastern Europe may support the idea that countries with a strong socialist tradition exhibit better gender balance. Several examples had a predominance of females in total authorships, including Macedonia, Latvia, Ukraine, and Bosnia and Herzegovina.

Figure 3 shows representation by gender and productivity. It shows persistent gender disparities in both representation and productivity in developed countries such as the USA, UK, Canada, and France. On the other hand, female authors are represented more frequently than males in developing countries or regions that include Hong Kong, Macau and Malaysia (though the relatively high per capita incomes prevalent in the former two should be acknowledged). The picture is reversed when productivity is considered. Future studies may examine the contradictory trends to understand the nature of collaborations in countries in Asia both developed and developing.

Some anomalies are evident. The biggest gender disparity is evident in Israel. Significant disparities also exist across European countries, notably in the case of Austria, Portugal, Norway, the Netherlands, and France; Sweden and Italy are exceptions in Europe. Hong Kong shows higher female than male representation; however, male productivity is almost double than what applies to females. The only reversals of productivity disparities apply to China and Portugal, although it should be noted that females are represented less than males. Despite these anomalies, representation and productivity related gender disparities in these countries may be attributable to the Matilda effect, with its emphasis on female positions in society (Rossiter, 1993). 
Insert figure 3 about here

\section{Gender Representation in Academic Journals}

Refereed scholarly journals are an important component of academic life, since publications are relevant for University hiring and promotion processes, as well as for funding, appointments, library subscriptions and the ranking of schools, countries, and scholars. This has led to the creation of ranking systems for academic journals, with relatively more and less prestigious publications. The well-known Social Science Citation Index (SSCI) ranking system is based on the impact factor of journals and is calculated using numbers of citations and of published articles. Ghiasi et al. (2018) found that "when women are listed as first authors, their papers receive lower citation rates than their male peers, despite having a similar number of authors and published in journals with higher SJR rankings." (p. 792). The same authors attributed this to the Matilda effect. Consequently, the present current study proposes that female authors are less represented than male authors when comparing both SSCI and non-SSCI-indexed journals. Moreover, females are less represented as first authors than males when SSCI and non-SSCI listed journals are compared. The database for the present study includes seven journals not indexed in SSCI, based on the Journal Citation Report 2017 and 18 SSCI indexed journals. All non-SSCI journals and the first eight SSCI journals have been considered in order to assess any gender disparities in journal classification, based on the impact factors that were reported in Journal Citation Report 2017. As is indicated in Table 3, female authors are less represented than males when comparing all journals, and female authors are also less represented than males as first authors. This may reflect the lesser 
recognition that is accorded to female authors in the academic journal environment than to their male counterparts.

Insert table 3 about here

\section{The Gender Composition of Collaborative Teams}

The size and gender composition of research teams plays a critical role in the creation and dissemination of knowledge. The number of authors in a collaborative team is an indicator of intellectual contribution, quality of output, and professionalism in the field (Koseoglu, 2016a). The current dataset shows that many collaborative articles include two or three authors. Only $13.47 \%$ of articles in the current database included four or more authors. These findings are consistent with previous hospitality and tourism studies (Benckendorff, 2010; Leung and Law, 2006; Roberts, 1998; Sheldon, 1991; Ye et al., 2013; Youn et al., 2011; Zhao and Ritchie, 2007).

The gender composition in research collaborations may reflect the complexity of intellectual structure, since females and males have distinct styles of thinking and working. For example, various empirically based studies have shown the different cognitive abilities by gender. While women's brains show more white matter, representing the networking of these processing centres, men's brains have more grey matter, representing information processing centres related to cognitive ability (Rhoten and Pfirman, 2007; Rhoten, 2007). This points to the different behaviors and thoughts of females and males that generate distinct work styles. Hence, analyzing gender composition in collaborative teams helps to identify the complexity of intellectual contributions in the field. To analyze gender composition, the authors classified collaboration in the articles into those between only female authors (FF), only male authors (MM), and at least one 
male and female (MX) author. The analysis of gender composition in collaborations demonstrates that $\mathrm{MM}$ collaborative articles have the strongest representation during the early periods; however, this percentage declined during the third period (1997-2001) and has continued to fall. MM collaborations accounted for over $60 \%$ of the outputs in the early period (before 1992) and this had halved to below $30 \%$ by the most recent period (2012-2016). During the same period there was a strong growth in MX collaborations (from about 30\% to over 60\%) and in FF collaborations (up to a more modest 10\% (Figure 4)). The good news is that the scale of collaborations between men and women has been increasing steadily, apparently at the expense of the previously dominant male only collaborations.

A further analysis was conducted to explore the composition of the MX collaborative articles by gender (Figure 4). The respective contributions were relatively balanced during the first two periods. By the third period the number of female authors in the MX collaborative articles was higher than for males, though gender disparities emerged during the latter two periods (Figure 4). This may reflect a tendency for female hospitality and tourism authors to collaborate increasingly with men, perhaps to acquire the social capital that is necessary to access both the formal and informal networks, resources, and opportunities that progress career development (Rhoten and Pfirman, 2007). Such approaches may be prevalent because males dominate significant or key positions in academia generally and also within the academic journal environment. It is worth noting that the data supports the receptiveness of male academics to the trend towards more collaborations across genders.

Insert figure 4 about here 


\section{Articles with International Collaborations}

An increase has been observed in international scientific collaborations over recent years (Iefremova et al., 2016; Larivière et al., 2013; Wang et al., 2015). This has led researchers to pay relatively more attention to international collaborations in order to identify, understand and explain this trend, its implications and impacts. It has been reported that international collaborative articles are cited more frequently, are of higher quality, and enjoy greater visibility for their findings (Koseoglu, 2016b). Wagner et al., (2018) have also shown that the research which is generated through international collaborations is more conceptually oriented. For the preceding reasons, engagement in international collaborations is potentially beneficial for both male and female researchers. Continuing efforts to address the gender composition of international collaborations may be important as a potential counterweight to the local and historical forces that have shaped gender imbalances in the academic environment. Previous researchers have observed that female collaborations are less internationally oriented than their male equivalents (Larivière et al., 2013). It has also been noted that females are particularly marginalized within the culture and structure of traditional science (Rhoten and Pfirman, 2007). In the case of hospitality and tourism, there has been an increasing number of international collaborations in academic articles in recent years (Koseoglu, 2018; Okumus et al. 2019). Since hospitality and tourism is a fundamentally global phenomenon for which global solutions are needed, it lends itself to cross-border research collaborations.

It was in light of the preceding observations, that the current researchers examined the gender compositions of both national and of international collaborative publications. To ensure full coverage, the authors classified the various articles into one of three groups: two or more 
authors from one institution and from one country, two or more authors from at least two different institutions from one country, and two or more authors from two or more institutions and two or more countries. The analysis shows that FF collaborative articles are produced more through national collaborations and through a single institution (48.43\%). Smaller proportions of the total output are produced via international collaborations $(33.54 \%$ of $\mathrm{MM}$ and $35.36 \%$ of $\mathrm{MX}$ collaborative articles as is noted in Figure 5). The percentages of female and male authors in the MX internationally collaborative articles were $49.23 \%$ and $50.77 \%$, respectively. These findings reflect Larivière et al.'s (2013) observation about the greater domestic-orientation of FF collaborations; MX international collaborations have however increased slightly over time. The percentage of females in MX internationally collaborative articles increased slightly and almost equally with male percentages during the overall period. This may indicate that the hospitality and tourism field is becoming better placed to generate more innovative and boundary-crossing research through international research collaborations because of the more balanced gender composition of the authorships. The gender composition finding prompts a further research question that draws upon the work of Wagner et al. (2018), namely how does gender composition affect the novelty and/or conventionality of articles?

Insert figure 5 about here

\section{Gender Positioning in Collaborative Teams}

As was noted in the methodology section, collaborative articles within a given field generate co-authorship networks (Koseoglu et al., 2016). Analyzing co-authorship networks may explain the tendency of CS participants to collaborate, the critical actors within the community, 
and the critical positions of actors across the community (Liu and Gan, 2018). Previous authors have observed that females may be more inclined towards scientific collaboration than males (Rhoten and Pfirman, 2007), though male authors often hold more important positions within coauthorship networks (Ghiasi et al., 2018).

To explore gender positioning in hospitality and tourism, this study first examined any gender related changes in the major components of co-authorship networks. A co-authorship network may be understood as a series of components, including actors who are directly or indirectly interconnected (González-Teruel et al., 2015). The networks that have the biggest component(s) connected to the largest number of actors in the network are both extensive and intimate (Ye et al., 2013), and include the most prolific researchers (Kretschmer, 2004). When gender disparities are examined in the main components of the network during the first period (before 1992), it is evident that the percentage of female authors $(20.54 \%)$ is less than the male equivalent (79.45\%). Though the prevalent disparity in the largest component decreased slightly through the last period, no significant changes were detected when the final three periods are considered in aggregate. This may reflect the strong structure of the largest component, and that males occupy strategic positions in managing the community. It is evident that females faced barriers to joining this component during the final two periods, thus prompting some additional research questions: are there barriers in place to females who want to collaborate with male hospitality and tourism authors? if yes, what are they? how do such barriers relate to rank or academic careers? and how can they be eliminated or minimized? These important questions are outside the scope of the present investigation.

The second measurement for investigating gender positioning in co-authorship networks involves calculating the average clustering coefficient (ACC) to demonstrate "how close one 
node's neighbours are to being a clique. Put simply, it describes the probability that one's friend's friend is also a friend of oneself. $C=0$ means that all the nodes are isolated, whereas $C=1$ means that all the nodes are directly connected" (Ye et al., 2013, p. 58). At the individual, node, or author level, the clustering coefficient (CC) shows "to what extent an author is important — nodes with a lower CC play more important linking roles in the network" (Ghiasi et al., 2018, p. 796). The current analysis revealed no significant disparities between female and male authors over time (see Figure 6). Female authors held lower CCs than males in the first period; however, this situation was reversed after the second period and was carried through until the final period. In other words, male authors occupied more important positioning than females in the third, fourth, and fifth periods, though both genders occupy almost equally important positions in the final period. This differs from the findings of Ghiasi et al. (2018) and raises the following question: although the number and/or productivity of female authors is less than males in the community, how do females hold an almost equally important position in the network? It may emerge that the relevant characteristic relates to hospitality and tourism which is widely viewed as a female profession, albeit with a legacy of men occupying key leadership roles (Basurto-Barcia and Ricaurte-Quijano, 2017).

\section{Insert figure 6 about here}

Degree centrality is the third measurement of gender positioning in co-authorship networks. This shows the number of a researcher's collaborators within the network (Yan and Ding, 2009), and the communication activities and popularity of authors (Abbasi et al., 2011a). An application of degree centrality analysis (Figure 7), indicated significant divergence from the 
conclusions of Ghiasi et al. (2018). The latter concluded that female authors commonly collaborate more than their male peers, based on the evidence of higher degree centrality. One parallel which may help to explain the results is Ghiasi et al.'s (2018) examination of Canadian initiatives to encourage and motivate female scientists in the nanotechnology field which they concluded had some beneficial results. The present analysis shows that male hospitality and tourism authors are on average more collaborative than females, and that the gap has increased over time. This may suggest a lack of initiatives to encourage female advancement within the hospitality and tourism scholarly field as well as some authority-related legacies.

Insert figure 7 about here

In the following section and as is reported in Figure 8, the authors present a visualization of the co-authorship network for all periods from 1965 to 2016. Blue nodes represent male authors and orange nodes represent females. These visualizations are based on the degree centrality of the authors. The network on the left side includes authors who have at least 20 connections. The network on the right side includes authors with at least 50 degrees. This visualization is based on the Fruchterman-Reingold algorithm which has been defined as: a "force-directed method using both attractive and repulsive forces in order to place the nodes of a network over a 2D or 3D space" (Silva et al., 2013, p. 472). As has been evidenced by Ghiasi et al. (2018), the network visualizations presented in the current study show that male authors are highly central in larger components and female authors are more central in the smaller components. The degree of specialization may be higher in the case of female authors. It has previously been observed that women have expertise in highly specialized areas, thereby prompting invitations to collaborate 
(Ghiasi et al., 2018). The persistent centrality of males in larger components may also be attributable to the longer established opportunities that they have had to chair and serve on $\mathrm{PhD}$ committees. The doctoral dissertations that have been supervised by the predominantly male senior academics from early in the review period may for example have generated publications with a wider group of co-authors.

Evidence of repeat collaborations between two male authors is more prevalent in the networks than the equivalent between two female authors. Repeat collaborations between one male and one female author are also more prevalent than between two female authors. This may reflect the favouring and dominance of male hospitality and tourism authors, consistent with previous findings about the nanotechnology field (Ghiasi et al., 2018). Female researchers may be attempting to connect or collaborate with central male authors in order to obtain greater acceptance from academic journals and to acquire greater recognition.

\section{Insert figure 8 about here}

The fourth measurement of the in-depth analysis of patterns is betweenness centrality. The network attributes provide an identification of those who are central to the network. A high betweenness score shows a hierarchical network structure, in which a single or a small number of nodes in the network tend to be more central, relative to others (Ying and Xiao, 2012). Table 4 lists the top 50 authors in the overall network with female authors displayed in bold. Based on the betweenness centrality score, there are only seven female contributors amongst 50 top authors. This highlights a small core of female contributors who have occupied central roles within the hospitality and tourism research environment. 
Insert table 4 about here

The existence of cliques within the overall network is the final measurement to identify the formation of research groups. A clique is defined as "a subgroup in which all its nodes are directly connected to each (while a cluster is a group of the same or similar elements gathered or occurring closely together)" (Abbasi et al., 2011b, p. 698). Table 5 lists the 17 strongest cliques across the overall network. The authors have defined a clique as including at least seven authors. Female authors are shown in bold. The listing indicates that male authors dominate the cliques. Since there will be some division of labour amongst the contributors to the collaborative work, including a primary decision-maker, future studies may further explore the nature of such collaborative inter-relationships. This will prospectively provide greater insights about how and why these collaborations are emerging within the hospitality and tourism field.

Insert table 5 about here

\section{Conclusions}

This study has drawn upon publications in hospitality and tourism journals between 19652016, in order to examine gender disparities in scholarly hospitality and tourism collaborations. The findings have generated potentially important contributions for the hospitality and tourism literature and for policymakers. It is the first of its kind to use authorships and co-authorships as a basis for investigating gender disparities within the hospitality and tourism literature. The following implications are proposed: 


\section{Theoretical Implications}

First, although the incidence has been decreasing over time, the findings show substantial gender imbalances in hospitality and tourism knowledge production within academic journals. Broader influences may be at play because of the multidisciplinary character of hospitality and tourism since with hospitality and tourism-focused journals including publications that are authored by scholars from both within and from outside the hospitality and tourism academy. There is a continuing need for research that will explain the effects of the multidisciplinary character of hospitality and tourism on gender disparities.

Previous researchers have investigated the influence of factors such as age, gender, race, education, ethnicity, and values on the forms and/or structures of social network relationships (Abt and Knyphausen-Aufseß, 2017; Badar et al., 2016; Badar et al., 2013; Barnes et al., 2017; Gallivan and Ahuja, 2015; McPherson et al., 2001). The present study found that homophily collaborations (between female and female or male and male authors) occurred less frequently than heterophilic collaborations (between male and female authors) (Badar et al., 2016). Also, the heterophilic trend has served to increase the production of hospitality and tourism knowledge. The present authors have also observed that more articles were produced by heterophilic than by homophilic collaborations. However, the percentage $(59.68 \%)$ of articles produced by heterophilic collaborations in non-SSCI journals was higher than the equivalent percentage in SSCI journals (50.68\%). The evidence indicates that, while heterophilic collaborations may be more effective from the perspective of productivity, homophilic collaborations between male and males may have greater impact. However, this conclusion merits further testing with the use of more advanced statistical tools that can yield greater detail.

\section{Practical Implications}


The study findings present decision-makers and policymakers with potentially relevant and data-driven analyses (Ghiasi et al., 2018). For example, the authors have shown that there is a smaller proportion of female contributors to SSCI journals than to their non-SSCI equivalents. Consequently, it is suggested that the editors of high-impact journals, in their capacity as gatekeepers of critical channels of knowledge dissemination, have a role to play in addressing gender disparities. Noting the persistent predominance of male journal editors, they may, for example, encourage female researchers by extending invitations as guest editors for special issues and increasing their active involvement in relevant research groups working on invited papers. The study has also identified gender disparities by country and/or region. Hospitality and tourism policymakers may focus on formulating strategies to address persistent inequities by modelling what has occurred in countries and regions that exhibit lower disparities. The UK-based Women in Tourism network brings together both academics and industry professionals and can serve as an example of building networking capacities that can generate impactful research and extend beyond academia (Women in Tourism, 2019).

The research findings have shown the applicability of the Matilda effect and the leaky pipeline theory within the hospitality and tourism academic community. Given the persistence of such phenomena, Universities and other research institutions may develop incentive schemes that cultivate and retain female academics. Universities or schools/colleges might, for example, refine their performance indicators to encourage collaborations between female and male researchers (in the way that male academics support capacity building by participating as mentors in some women in leadership initiatives). One potential initiative could involve additional credit for co-authored publications by male and female researchers in top-tier journals. Another study finding has been that female authors have relatively weak ties within co-authorship networks. Hospitality and 
tourism schools may respond by designing policies that strengthen diversity with a view to increasing productivity in knowledge creation and dissemination. Finally, the data show lower than average collaboration by female authors than by males, which is contrary to Ghiasi et al.'s (2018) conclusions. These contributors observed the opposite phenomenon in the case of nanotechnology. Researchers should explore why females appear to be less collaborative in hospitality and tourism with a view to designing appropriate and evidence based policies to guide academic research.

\section{Limitations and Prospects for Future Research}

This study has a number of limitations. First, the authors have used 25 English-language hospitality and tourism journals. Future studies may include a wider range of publications drawing from complementary knowledge domains, either in English or in other languages. Second, this study examined only gender disparities in collaborations that were generated by productive authors with at least ten co-authored articles published in the selected journals. Single authored papers have not been considered. Future researchers may explore gender disparities across all author collaborations within the environment of academic journals. Third, regarding authorship order, this study considered the last authorship position as an important position due to the seniority of the applicable authors. However, the ordering of authors may be based on total contributions. On this basis, the last author may have made the least contribution to the article compared with the principal or senior author (Ghiasi et al., 2018). Fourth, this study has adopted five-year time spans to identify potentially changing disparities. Future studies may consider investigating the evolutionary process using different time spans. Fifth, this study did not consider the effects of the numbers of women entering hospitality academia, or the time that it takes to be promoted from assistant professor to associate professor and then to full professor. It seems reasonable to assume 
that there were relatively fewer female hospitality and tourism academics in the earlier period (e.g. the 1990s), compared with now. This would have resulted in fewer women to produce articles and also to continue into senior academic roles. Future studies may be conducted on these two issues. Finally, subjectivity may have played a part in how the networks have been defined and interpreted, leading to potential interpretative bias.

The study findings suggest potential research opportunities. Researchers are encouraged to address the various questions that were posed in the results and discussion section. Second, they may address hospitality and tourism gender disparities by focusing on prevailing related gender public policies in specific countries and regions. Third, researchers may investigate network visualizations are changing through different periods in order to examine the structuring of clusters within networks around potential gender-based disparities. Fourth, it may be timely for hospitality and tourism researchers to give greater consideration to the impacts of papers published in top tier journals that go beyond academic citations, notably to the impacts and influence on industry and on policymaking. Research impacts are now measured in the relevant territory-wide research quality assessment exercises in the UK and in Hong Kong, an indicator of their growing importance as indicators for policymaking and research quality. Fifth, this study explored the structure of collaboration networks in the hospitality and tourism field based on gender. However, further analysis of the phenomenon is needed - researchers should make use of primary data to investigate the how and why of inequalities (imbalances) in scholarly collaborations. Finally, it is suggested that researchers can replicate the present study in the context of other disciplines or fields. 


\section{References}

Abbasi, A., Altmann, J., and Hossain, L. (2011a), "Identifying the effects of co-authorship networks on the performance of scholars: A correlation and regression analysis of performance measures and social network analysis measures", Journal of Informetrics, Vol. 5, pp. 594-607.

Abbasi, A., Hossain, L., Uddin, S. and Rasmussen, K.J.R. (2011b), "Evolutionary dynamics of scientific collaboration networks: multi-levels and cross-time analysis", Scientometrics, Vol. 89 No. 2, pp. 687-710.

Abramo, G., D'Angelo, C. A., and Murgia, G. (2013), "Gender differences in research collaboration", Journal of Informetrics, Vol. 7, pp. 811-822.

Abt, M. and Knyphausen-Aufseß, D. Z. (2017), "Chief human resources officers on top management teams: An empirical analysis of contingency, institutional, and homophily antecedents", Business Research, Vol. 10, pp. 49-77.

Ahmed, T., Ahmed, A., Ali, M., and Kamran, M. (2017), "Analysis of co-authorship in computer networks using centrality measures", In Communication, Computing and Digital Systems (C-CODE), International Conference on (pp. 54-57): IEEE.

Ateljevic, I., Pritchard, A., and Morgan, N. (Eds.). (2007), The critical turn in tourism studies. Routledge.

Badar, K., Frantz, T. L., and Jabeen, M. (2016), "Research performance and degree centrality in co-authorship networks: The moderating role of homophily", Aslib Journal of Information Management, Vol. 68, pp. 756-771.

Badar, K., Hite, J. M., and Badir, Y. F. (2013), "Examining the relationship of co-authorship network centrality and gender on academic research performance: The case of chemistry researchers in Pakistan", Scientometrics, Vol. 94, pp. 755-775.

Bagilhole, B. and White, K. (Eds.). (2013), Generation and gender in academia. Springer.

Barnes, S., Sang, K. J., and Baruch, Y. (2017), "Homophily in human resource management publishing", European Management Review, Vol. 14, pp. 287-302.

Basurto-Barcia, J. and Ricaurte-Quijano, C. (2017), "Women in tourism: Gender (in)equalities in university teaching and research", Anatolia, Vol. 28, pp. 567-581.

Benckendorff, P. (2010), "Exploring the limits of tourism research collaboration: A social network analysis of co-authorship patterns in Australian and New Zealand tourism research", In Paper presented at the CAUTHE 2010: Tourism and Hospitality: Challenge the Limits.

Bornmann, L., Mutz, R., and Daniel, H. D. (2007), "Gender differences in grant peer review: A meta-analysis", Journal of Infometrics, Vol. 1, pp. 226-238.

Bozeman, B. and Corley, E. (2004), "Scientists' collaboration strategies: Implications for scientific and technical human capital", Research Policy, Vol. 33, pp. 599-616.

Buchan, A. M., Jurczyk, E., Isserlin, R., and Bader, G. D. (2016), "Global neuroscience and mental health research: a bibliometrics case study", Scientometrics, Vol. 109, pp. 515-531.

Clark Blickenstaff, J. (2005), "Women and science careers: leaky pipeline or gender filter?", Gender and education, Vol. 17 No. 4, pp. 369-386.

Clement, T. P. (2014), "Authorship matrix: a rational approach to quantify individual contributions and responsibilities in multi-author scientific articles", Science and Engineering Ethics, Vol. 20, pp. 345-361.

Dehdarirad, T. and Nasini, S. (2017), "Research impact in co-authorship networks: A two-mode analysis", Journal of Informetrics, Vol. 11, pp. 371-388. 
Dotson, B. (2011), “Women as authors in the pharmacy literature: 1989-2009”, American Journal of Health-System Pharmacy, Vol. 68, pp. 1736-1739.

Ek, R. and Larson, M. (2017), "Imagining the Alpha male of the tourism tribe", Anatolia, Vol. 28 No. 4, pp. 540-552.

Elsevier. (2017). Gender in the global research landscape. Retrieved August 4, 2017, from http://www.elsevier.com/__data/ assets/pdf_ le/0008/265661/ElsevierGenderReport_ nal_for-web.pdf.

Figueroa-Domecq, C., Pritchard, A., Segovia-Pérez, M., Morgan, N., and Villacé-Molinero, T. (2015), "Tourism gender research: A critical accounting", Annals of Tourism Research, Vol. 52, pp. 87-103.

Galegher, J., Egido, C., and Kraut, R. E. (2014), Patterns of contact and communication in scientific research collaborations. In Intellectual Teamwork (pp. 163-186): Psychology Press.

Gallardo-Gallardo, E., Arroyo Moliner, L., and Gallo, P. (2017), "Mapping collaboration networks in talent management research", Journal of Organizational Effectiveness: People and Performance, Vol. 4, pp. 332-358.

Gallivan, M. and Ahuja, M. (2015), "Co-authorship, homophily, and scholarly influence in information systems research", Journal of the Association for Information Systems, Vol. 16 No. 12, pp. 980-1015.

Gaughan, M. and Bozeman, B. (2016), "Using the prisms of gender and rank to interpret research collaboration power dynamics”, Social Studies of Science, Vol. 46, pp. 536-558.

Ghiasi, G., Harsh, M., and Schiffauerova, A. (2018), "Inequality and collaboration patterns in Canadian nanotechnology: Implications for pro-poor and gender-inclusive policy", Scientometrics, Vol. 115, pp. 785-815.

González-Teruel, A., González-Alcaide, G., Barrios, M., and Abad-García, M.-F. (2015), "Mapping recent information behavior research: An analysis of co-authorship and cocitation networks", Scientometrics, Vol. 103, pp. 687-705.

Goulden, M., Mason, M. A., and Frasch, K. (2011), "Keeping women in the science pipeline", The Annals of the American Academy of Political and Social Science, Vol. 638 No. 1, pp. 141162.

Gursoy, D., and Sandstrom, J. K. (2016), “An updated ranking of hospitality and tourism journals", Journal of Hospitality \& Tourism Research, Vol. 40, pp. 3-18.

$\mathrm{Hu}, \mathrm{C}$., and Racherla, P. (2008), "Visual representation of knowledge networks: A social network analysis of hospitality research domain", International Journal of Hospitality Management, Vol. 27, pp. 302-312.

Husu, L. (2013). Interrogating gender paradoxes in changing academic and scientific organisation(s). In S. Strid, \& L. Husu (Eds.), GEXcel work in progress report volume XVIII. Proceedings from GEXcel emes 11-12. Visiting Scholars: Gender Paradoxes in Changing Academic and Scientifi c Organization(s). Retrieved August 4, 2017, from http:// www2.warwick.ac.uk/fac/soc/sociology/sta /academicsta /mariadomarpereira/ gexcel.pdf.

Iefremova, O., Sas, D., and Kozak, M. (2016), "International collaboration among authors of Current Science", Current Science, Vol. 110, pp. 1414.

Jagsi, R., Guancial, E. A., Worobey, C. C., Henault, L. E., Chang, Y., Starr, R., Tarbell, N. J., and Hylek, E. M. (2006), "The "gender gap" in authorship of academic medical literature-a 35-year perspective”, New England Journal of Medicine, Vol. 355, pp. 281-287. 
Jeffrey, H. L. (2017), "Gendering the tourism curriculum whilst becoming an academic", Anatolia, Vol. 28 No. 4, pp. 530-539.

Jung, J., Bozeman, B., and Gaughan, M. (2017), "Impact of research collaboration cosmopolitanism on job satisfaction", Research Policy, Vol. 46, pp. 1863-1872.

Knobloch-Westerwick, S. and Glynn, C. J. (2013), "The Matilda effect --Role congruity effects on scholarly communication: A citation analysis of Communication Research and Journal of Communication articles", Communication Research, Vol. 40 No. 1, pp. 3-26.

Knobloch-Westerwick, S., Glynn, C. J., and Huge, M. (2013), "The Matilda effect in science communication: an experiment on gender bias in publication quality perceptions and collaboration interest", Science Communication, Vol. 35 No. 5, pp. 603-625.

Koseoglu, M. A. (2018), "A new approach to journal ranking: social structure in hospitality and tourism journals", International Journal of Contemporary Hospitality Management, DOI: 10.1108/IJCHM-10-2017-0622.

Koseoglu, M. A. (2016a), "Growth and structure of authorship and co-authorship network in the strategic management realm: Evidence from the Strategic Management Journal", $B R Q$ Business Research Quarterly, Vol. 19, pp. 153-170.

Koseoglu, M. A. (2016b), "Mapping the institutional collaboration network of strategic management research: 1980-2014”, Scientometrics, Vol. 109, pp. 203-226.

Koseoglu, M. A., Rahimi, R., Okumus, F., and Liu, J. (2016), "Bibliometric studies in tourism”, Annals of Tourism Research, Vol. 61, pp. 180-198.

Kretschmer, H. (2004), "Author productivity and geodesic distance in bibliographic co-authorship networks, and visibility on the web", Scientometrics, Vol. 60, pp. 409-420.

Kumar, S. and Jan, J. M. (2013), "Mapping research collaborations in the business and management field in Malaysia, 1980-2010”, Scientometrics, Vol. 97, pp. 491-517.

L'Huillier, B. (2012), "Publish or perish", Accounting, Auditing \& Accountability Journal, Vol. 25 No. 6, pp. 1071-1071.

Larivière, V., Ni, C., Gingras, Y., Cronin, B., and Sugimoto, C. R. (2013), "Bibliometrics: Global gender disparities in science", Nature News, Vol. 504, pp. 211-213.

Leung, R., and Law, R. (2006), Analyzing the authorship of information technology publications in leading hospitality and tourism journals. In M. Hitz, M. Sigala \& J. Murphy (Eds.), Information and Communication Technologies in Tourism 2006: Proceedings of the International Conference in Lausanne, Switzerland, 2006 (pp. 13-25). Vienna: Springer Vienna.

Lincoln, A. E., Pincus, S., Koster, J. B., and Leboy, P. S. (2012), "The Matilda effect in science: Awards and prizes in the US, 1990s and 2000s", Social Studies of Science, Vol. 42, pp. 307-320.

Liu, S. C.-H. and Gan, B. (2018), "Creating a competitive advantage by occupying critical position: Analysis of the tourism academy network in Taiwan", Journal of Hospitality \& Tourism Research, Vol. 42, pp. 102-121.

McPherson, M., Smith-Lovin, L., and Cook, J. M. (2001), "Birds of a feather: Homophily in social networks", Annual Review of Sociology, Vol. 27, pp. 415-444.

Munar, A. M. (2017), "To be a feminist in (tourism) academia", Anatolia, Vol. 28 No. 4, pp. 514529.

Munar, A. M., Biran, A., Budeanu, A., Caton, K., Chambers, D., Dredge, D., ... and Nygaard, L. (2015), "The gender gap in tourism academy: Statistics and indicators of gender equality", While Waiting for the Dawn. 
Munoz, D. A., Queupil, J. P., and Fraser, P. (2016), "Assessing collaboration networks in educational research: A co-authorship-based social network analysis approach", International Journal of Educational Management, Vol. 30, pp. 416-436.

Nunkoo, R., Hall, C. M., and Ladsawut, J. (2017), Vol. Gender and choice of methodology in tourism social science research", Annals of Tourism Research, Vol. 63, pp. 207-210.

Okumus, F., Köseoglu, M. A., Putra, E. D., Dogan, I. C., and Yildiz, M. (2019), "A Bibliometric Analysis of Lodging-Context Research From 1990 to 2016", Journal of Hospitality \& Tourism Research, Vol. 43 No. 2, pp. 210-225.

Perryman, A. A., Fernando, G. D., and Tripathy, A. (2016), "Do gender differences persist? An examination of gender diversity on firm performance, risk, and executive compensation", Journal of Business Research, Vol. 69, pp. 579-586.

Pritchard, A., and Morgan, N. (2017), "Tourism's lost leaders: Analysing gender and performance", Annals of Tourism Research, Vol. 63, pp. 34-47.

RAND. (2005), Is there gender bias in federal grant programs? (RAND Infrastruc- ture, Safety, and Environment Research Brief No. RB-9147-NSF). Retrieved from http://rand.org/pubs/research_briefs/RB9147/RAND_RB9147.pdf.

Rhoten, D. and Pfirman, S. (2007), "Women in interdisciplinary science: Exploring preferences and consequences", Research policy, Vol. 36, pp. 56-75.

Roberts, C. (1998), "Academic authorship trends in hospitality and business journals", Journal of Hospitality \& Tourism Education, Vol. 10, pp. 56-61.

Rossiter, M. W. (1993), "The Matthew Matilda effect in science”, Social Studies of Science, Vol. 23, pp. 325-341.

Saunders, D. M. (2002), This was never meant to be a career: Gender and Monopsony in Academic Labor Markets (Paper presented at Eastern Economics Association Meetings, Boston, Massachusetts, March, 2002).

Scharber, C., Pazurek, A., and Ouyang, F. (2019), "Illuminating the (in)visibility of female scholars: A gendered analysis of publishing rates within educational technology journals from 2004 to 2015", Gender and Education, Vol. 31 No. 1, pp. 33-61.

Serrat, O. (2017), Social network analysis. In Knowledge solutions: Tools, methods, and approaches to drive organizational performance (pp. 39-43). Singapore: Springer Singapore.

Sheldon, P. J. (1991), "An authorship analysis of tourism research", Annals of Tourism Research, Vol. 18, pp. 473-484.

Silva, F. N., Rodrigues, F. A., Oliveira, O. N., and da F. Costa, L. (2013), "Quantifying the interdisciplinarity of scientific journals and fields", Journal of Informetrics, Vol. 7, pp. 469-477.

Smith, P., Caputi, P., and Crittenden, N. (2012), "A maze of metaphors around glass ceilings", Gender in Management: an international journal, Vol. 27 No. 7, pp. 436-448.

Swain, M. B., and Momsen, J. H. (Eds.). (2002), Gender/tourism/fun (?). Cognizant Communication Corporation.

UMYC (2011), White Paper on the Position of Women in Science in Spain, available from http://www.idi.mineco.gob.es/stfls/MICINN/Ministerio/FICHEROS/UMYC/WhitePaper Interactive.pdf.

Wagner, C. S., Whetsell, T. A., and Mukherjee, S. (2018), "Novelty and conventionality in international research collaboration", arXiv preprint arXiv:1804.09070. 
Waltman, L. (2012), "An empirical analysis of the use of alphabetical authorship in scientific publishing", Journal of Informetrics, Vol. 6, pp. 700-711.

Wang, L., Thijs, B., and Glänzel, W. (2015), "Characteristics of international collaboration in sport sciences publications and its influence on citation impact", Scientometrics, Vol. 105, pp. 843-862.

Ward, K. B., Gast, J., and Grant, L. (1992), "Visibility and dissemination of women's and men's sociological scholarship", Social Problems, Vol. 39 No. 3, pp. 291-298.

West, J. D., Jacquet, J., King, M. M., Correll, S. J., and Bergstrom, C. T. (2013), "The role of gender in scholarly authorship", PloS one, Vol. 8, pp. e66212.

Women in Tourism (2019) Retrieved May 21, 2019, from http://www.womenintourism.co.uk/

World Economic Forum. (2016), e global gender gap report. Geneva. Retrieved August 4, 2017, from http://www3. weforum.org/docs/GGGR16/WEF_Global_Gender_Gap_Report_ 2016.pdf

Yan, E. and Ding, Y. (2009), “Applying centrality measures to impact analysis: A coauthorship network analysis", Journal of the Association for Information Science and Technology, Vol. 60, pp. 2107-2118.

Ye, Q., Li, T., and Law, R. (2013), “A co-authorship network analysis of tourism and hospitality research collaboration", Journal of Hospitality \& Tourism Research, Vol. 37, pp. 51-76.

Ye, Q., Song, H., and Li, T. (2012), "Cross-institutional collaboration networks in tourism and hospitality research”, Tourism Management Perspectives, Vol. 2-3, pp. 55-64.

Ying, T. and Xiao, H. (2012), "Knowledge linkage: a social network analysis of tourism dissertation subjects", Journal of Hospitality and Tourism Research, Vol. 36 No. 4, pp. 450-477

Youn, H., Johanson, M. M., and Woods, R. H. (2011), “Authorship trends and perspectives within the hospitality and tourism academy", Journal of Hospitality \& Tourism Education, Vol. 23, pp. 44-50.

Yuan, Y. C. and Gay, G. (2006), "Homophily of network ties and bonding and bridging social capital in computer-mediated distributed teams", Journal of Computer-Mediated Communication, Vol. 11, pp. 1062-1084.

Zhao, W. and Ritchie, J. R. B. (2007), "An investigation of academic leadership in tourism research: 1985-2004", Tourism Management, Vol. 28, pp. 476-490.

Zoghbi, H. Y. and Greengard, P. (2014), "What Women Need to Succeed in Science", Scientist, Vol. 28 No. 2, pp. 26-27.

Zupic, I. and Čater, T. (2015), "Bibliometric methods in management and organization", Organizational Research Methods, Vol. 18, pp. 429-472. 
Table 1. Sample

\begin{tabular}{|c|c|c|c|c|c|}
\hline Selected Journals & Earliest issue & Latest issue & $\begin{array}{l}\text { \# of } \\
\text { articles }\end{array}$ & $\begin{array}{l}\# \text { of } \\
\text { articles in } \\
\text { the } \\
\text { sample }\end{array}$ & $\begin{array}{l}\% \text { of } \\
\text { articles in } \\
\text { the sample }\end{array}$ \\
\hline Anatolia: An International Journal of Tourism and Hospitality Research (Anatolia) & 1997- v8(3) & 2016-v27(4) & 427 & 137 & 32.08 \\
\hline Asia Pacific Journal of Tourism Research (APJTR) & 1996-v1(1) & 2016-v21(12) & 650 & 325 & 50.00 \\
\hline Annals of Tourism Research (ATR) & 1973-v1(1) & 2016-6-v61 & 2297 & 738 & 32.13 \\
\hline Cornell Hospitality Quarterly $(\mathrm{CHQ})$ & 1960-v1(1) & 2016-v57(4) & 2430 & 638 & 26.26 \\
\hline Current Issues in Tourism (CIT) & 1998-v1(1) & 2016-v19(14) & 666 & 242 & 36.34 \\
\hline International Journal of Contemporary Hospitality Management (IJCHM) & 1989-v1(1) & 2016-v28(12) & 1199 & 547 & 45.62 \\
\hline International Journal of Culture, Tourism and Hospitality Research (IJCTHR) & 2007-v1(1) & 2016-v10(4) & 265 & 77 & 29.06 \\
\hline International Journal of Hospitality Management (IJHM) & 1997-v1(1) & 2016-v59 & 1710 & 929 & 54.33 \\
\hline International Journal of Hospitality and Tourism Administration (IJHTA) & 1997-v1(1) & 2016-v17(4) & 345 & 167 & 48.41 \\
\hline International Journal of Tourism Research (IJTR) & 1999-v1(1) & 2016-v18(6) & 714 & 297 & 41.60 \\
\hline Journal of Destination Marketing \& Management (JDMM) & 2013-v1(1) & $2016-v 5(4)$ & 124 & 50 & 40.32 \\
\hline Journal of Hospitality Marketing \& Management (JHMM) & $1992-\mathrm{v} 1(1)$ & 2016-v25(8) & 667 & 331 & 49.63 \\
\hline Journal of Hospitality and Tourism Management (JHTM) & 2006-v13(1) & 2016-v29 & 228 & 87 & 38.16 \\
\hline Journal of Hospitality and Tourism Research (JHTR) & $1976-\mathrm{v} 1(1)$ & 2016-v40(6) & 920 & 453 & 49.24 \\
\hline Journal of Sustainable Tourism (JST) & 1993-v1(1) & 2016-v24(12) & 879 & 352 & 40.05 \\
\hline Journal of Travel and Tourism Marketing (JTTM) & 1992-v1(1) & 2016-v33(9) & 1598 & 583 & 36.48 \\
\hline Journal of Travel Research (JTR) & $1968-\mathrm{v} 7(1)$ & 2016-v55(8) & 1053 & 803 & 76.26 \\
\hline Journal of Vacation Marketing (JVM) & 1994-v1(1) & 2016-v22(4) & 591 & 249 & 42.13 \\
\hline Scandinavian Journal of Hospitality and Tourism (SJHT) & 2001-v1(1) & 2016-v16(4) & 315 & 80 & 25.40 \\
\hline Tourism Economics $(T E)$ & 1995-v1(1) & 2016-v22(6) & 979 & 351 & 35.85 \\
\hline Tourism Geographies (TG) & 1999-v1(1) & 2016-v18(5) & 453 & 127 & 28.04 \\
\hline Tourism Hospitality Research $(T H R)$ & 1999-v1(2) & 2016-v16(4) & 338 & 118 & 34.91 \\
\hline Tourism Management (TM) & 1999-v3(1) & 2016-v57 & 2463 & 962 & 39.06 \\
\hline Tourism Management Perspectives (TMP) & 2012-v1 & 2016-v20 & 269 & 90 & 33.46 \\
\hline Tourist Studies $(T S)$ & 2001-v1(1) & 2016-v16(4) & 238 & 18 & 7.56 \\
\hline Total & - & - & 21818 & 8751 & 40.11 \\
\hline
\end{tabular}


Table 2. Gender Representation in Collaborative Articles

\begin{tabular}{|c|c|c|c|c|c|c|c|}
\hline Periods & $\begin{array}{l}\text { Before } \\
1992 \\
\end{array}$ & $\begin{array}{l}1992- \\
1996 \\
\end{array}$ & $\begin{array}{l}1997- \\
2001 \\
\end{array}$ & $\begin{array}{l}2002- \\
2006 \\
\end{array}$ & $\begin{array}{l}2007- \\
2011 \\
\end{array}$ & $\begin{array}{l}2012- \\
2016 \\
\end{array}$ & $\begin{array}{l}\text { Over } \\
\text { All }\end{array}$ \\
\hline \# Articles & 580 & 575 & 961 & 1360 & 2113 & 3162 & 8751 \\
\hline \# Author Appearances & 1303 & 1370 & 2336 & 3386 & 5606 & 9232 & 23233 \\
\hline Ratio of female author appearances & 20.72 & 22.12 & 27.65 & 30.86 & 34.98 & 38.97 & 33.67 \\
\hline Ratio of male author appearances & 79.28 & 77.88 & 72.35 & 69.74 & 65.02 & 61.03 & 66.33 \\
\hline \# Author & 564 & 728 & 1151 & 1572 & 2329 & 3400 & 6765 \\
\hline Ratio of female authors & 23.76 & 27.47 & 32.58 & 38.04 & 42.42 & 43.56 & 41.66 \\
\hline Ratio of male authors & 76.24 & 72.53 & 67.42 & 61.96 & 57.58 & 56.44 & 58.34 \\
\hline \# Authors who contributed only once & 349 & 499 & 749 & 986 & 1381 & 1990 & 4057 \\
\hline Ratio of female contributed once & 22.62 & 29.86 & 36.45 & 42.80 & 45.98 & 45.28 & 43.18 \\
\hline Ratio of male contributed once & 77.38 & 70.14 & 63.55 & 57.20 & 54.02 & 54.72 & 56.82 \\
\hline
\end{tabular}


Table 3. Gender Representations in Academic

\begin{tabular}{|c|c|c|c|}
\hline $\begin{array}{l}\text { SSCI } \\
\text { status }\end{array}$ & Journals & $\begin{array}{l}\% \\
\text { female }\end{array}$ & $\%$ male \\
\hline \multirow{10}{*}{$\begin{array}{l}\text { Non-SSCI } \\
\text { journals }\end{array}$} & Anatolia & 37.77 & 62.23 \\
\hline & IJCTHR & 43.98 & 56.02 \\
\hline & IJHTA & 35.48 & 64.52 \\
\hline & $J H M M$ & 40.20 & 59.80 \\
\hline & JHTM & 45.87 & 54.13 \\
\hline & $T H R$ & 35.92 & 64.08 \\
\hline & $T M P$ & 40.87 & 59.13 \\
\hline & Total & 39.47 & 60.53 \\
\hline & As First & & \\
\hline & Author & 39.62 & 60.38 \\
\hline \multirow{11}{*}{$\begin{array}{l}\text { SSCI } \\
\text { journals }\end{array}$} & $A T R$ & 32.14 & 67.86 \\
\hline & $\mathrm{CHQ}$ & 28.17 & 71.83 \\
\hline & IJCHM & 33.52 & 66.48 \\
\hline & IJHM & 35.43 & 64.57 \\
\hline & JHTR & 30.81 & 69.19 \\
\hline & $J S T$ & 38.35 & 61.65 \\
\hline & JTR & 30.41 & 69.59 \\
\hline & $T M$ & 31.75 & 68.25 \\
\hline & Total & 32.41 & 67.59 \\
\hline & As First & & \\
\hline & Author & 34.90 & 65.10 \\
\hline
\end{tabular}


Table 4. Top authors based on betweenness centrality

\begin{tabular}{rlrrlr}
\hline Rank & Author & $\begin{array}{r}\text { Betweenness } \\
\text { Score }\end{array}$ & Rank & Author & $\begin{array}{r}\text { Betweenness } \\
\text { Score }\end{array}$ \\
\hline 1 & $\mathrm{~m} 1$ & 1606040.3 & 26 & $\mathrm{~m} 80$ & 468496.4 \\
2 & $\mathrm{~m} 33$ & 1192437.6 & 27 & $\mathrm{~m} 20$ & 462517.2 \\
3 & $\mathrm{~m} 57$ & 1052733.9 & 28 & $\mathrm{~m} 10$ & 460764.2 \\
4 & $\mathbf{f} 2$ & 915492.7 & 29 & $\mathbf{f 2 2}$ & 457475.8 \\
5 & $\mathrm{~m} 6$ & 865898.2 & 30 & $\mathrm{~m} 173$ & 452947.3 \\
6 & $\mathbf{f 1}$ & 857170.0 & 31 & $\mathbf{f 6 3}$ & 426042.6 \\
7 & $\mathrm{~m} 17$ & 846311.6 & 32 & $\mathrm{~m} 18$ & 414120.1 \\
8 & $\mathrm{~m} 39$ & 837410.5 & 33 & $\mathrm{~m} 76$ & 411657.8 \\
9 & $\mathrm{~m} 11$ & 810956.9 & 34 & $\mathrm{~m} 37$ & 399702.7 \\
10 & $\mathrm{~m} 9$ & 801109.1 & 35 & $\mathrm{~m} 26$ & 399110.9 \\
11 & $\mathrm{~m} 21$ & 798466.0 & 36 & $\mathrm{~m} 13$ & 398795.9 \\
12 & $\mathrm{~m} 15$ & 795224.1 & 37 & $\mathbf{f 5 1}$ & 395255.5 \\
13 & $\mathrm{~m} 24$ & 729124.6 & 38 & $\mathrm{~m} 157$ & 387431.7 \\
14 & $\mathrm{~m} 16$ & 702514.2 & 39 & $\mathrm{~m} 14$ & 384497.3 \\
15 & $\mathrm{~m} 8$ & 701152.9 & 40 & $\mathrm{~m} 79$ & 383660.2 \\
16 & $\mathrm{~m} 4$ & 690605.9 & 41 & $\mathrm{~m} 69$ & 375435.0 \\
17 & $\mathrm{~m} 19$ & 657870.7 & 42 & $\mathrm{~m} 41$ & 373446.4 \\
18 & $\mathrm{~m} 50$ & 601705.4 & 43 & $\mathbf{f 1 0}$ & 369971.5 \\
19 & $\mathrm{~m} 3$ & 595730.2 & 44 & $\mathrm{~m} 279$ & 367703.7 \\
20 & $\mathbf{f 1 0 4}$ & 592725.3 & 45 & $\mathrm{~m} 54$ & 367345.4 \\
21 & $\mathrm{~m} 44$ & 583453.4 & 46 & $\mathrm{~m} 22$ & 367279.4 \\
22 & $\mathrm{~m} 12$ & 581012.4 & 47 & $\mathrm{~m} 74$ & 363295.3 \\
23 & $\mathrm{~m} 5$ & 561009.3 & 48 & $\mathrm{~m} 110$ & 361888.8 \\
24 & $\mathrm{~m} 2$ & 540932.2 & 49 & $\mathrm{~m} 40$ & 357562.5 \\
25 & $\mathrm{~m} 28$ & 538232.1 & 50 & $\mathrm{~m} 62$ & 348423.3 \\
\hline & & & & &
\end{tabular}


Table 5: Cliques in the overall network

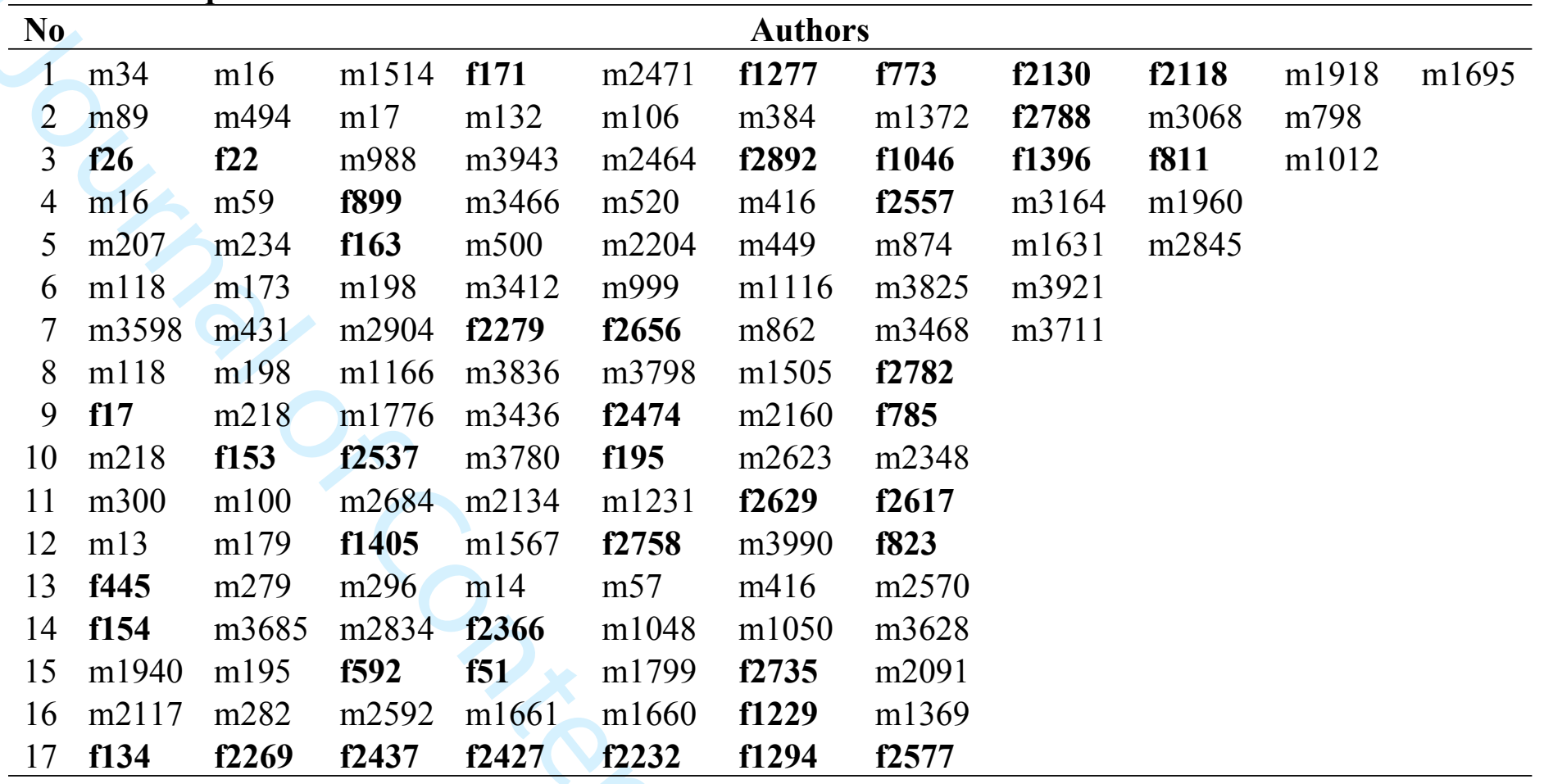




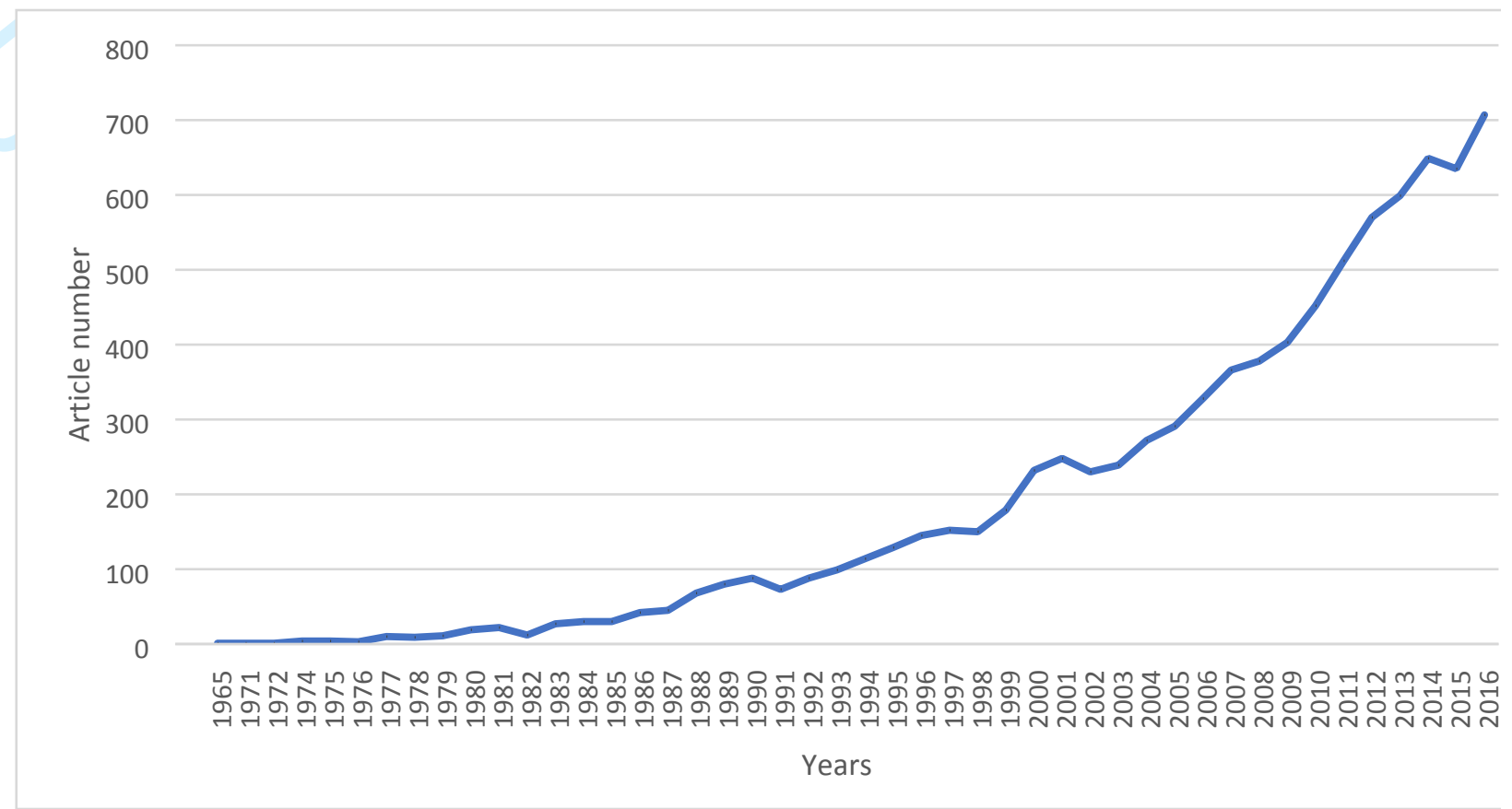

Figure 1. Incidence of articles over time. 


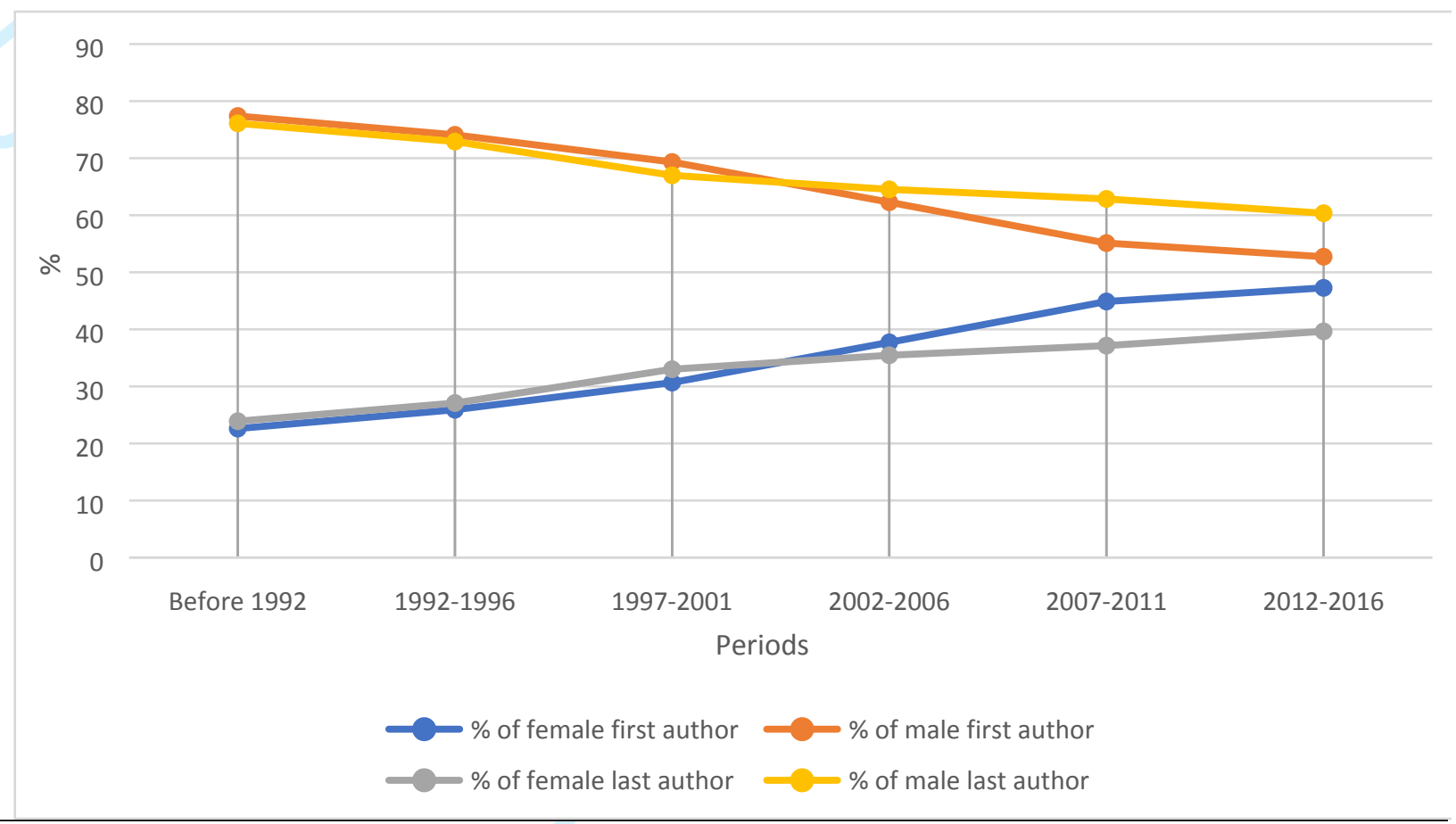

Figure 2. The genders of first and last authors in collaborative articles. 


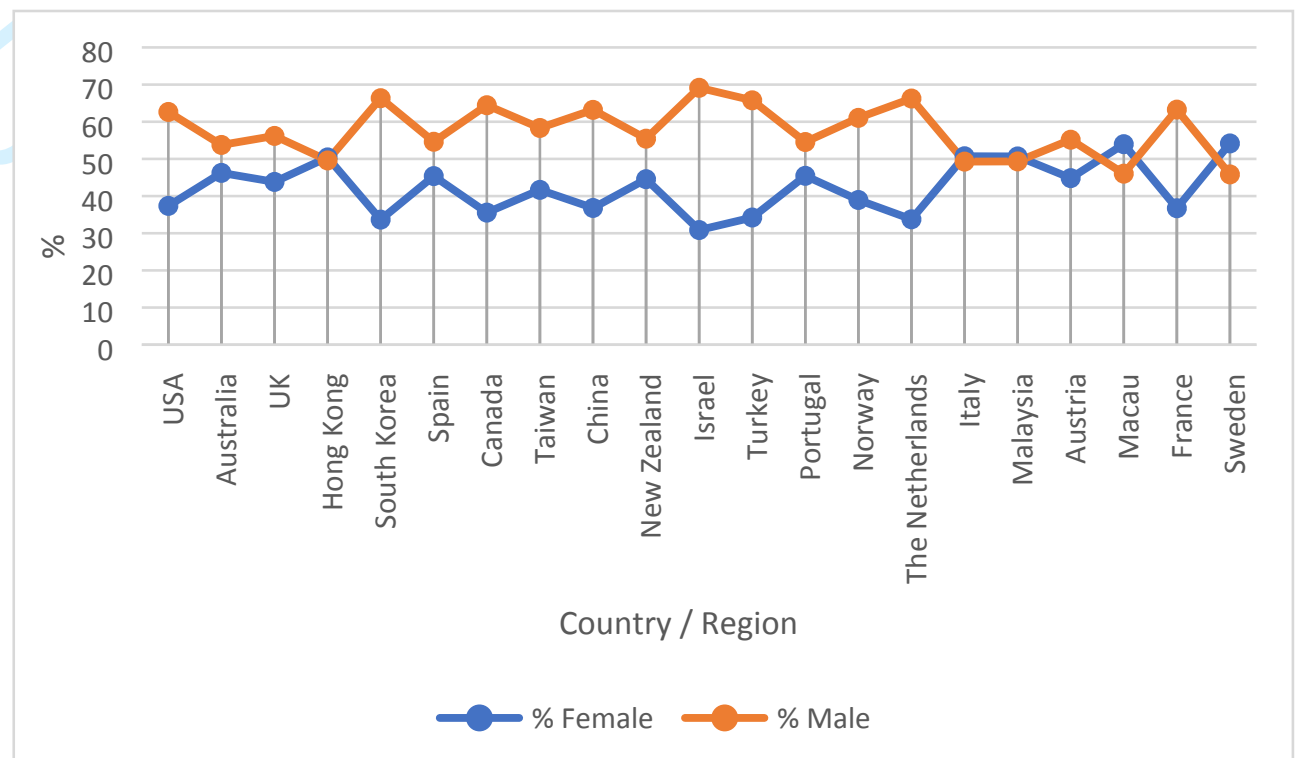

A- Gender Representations

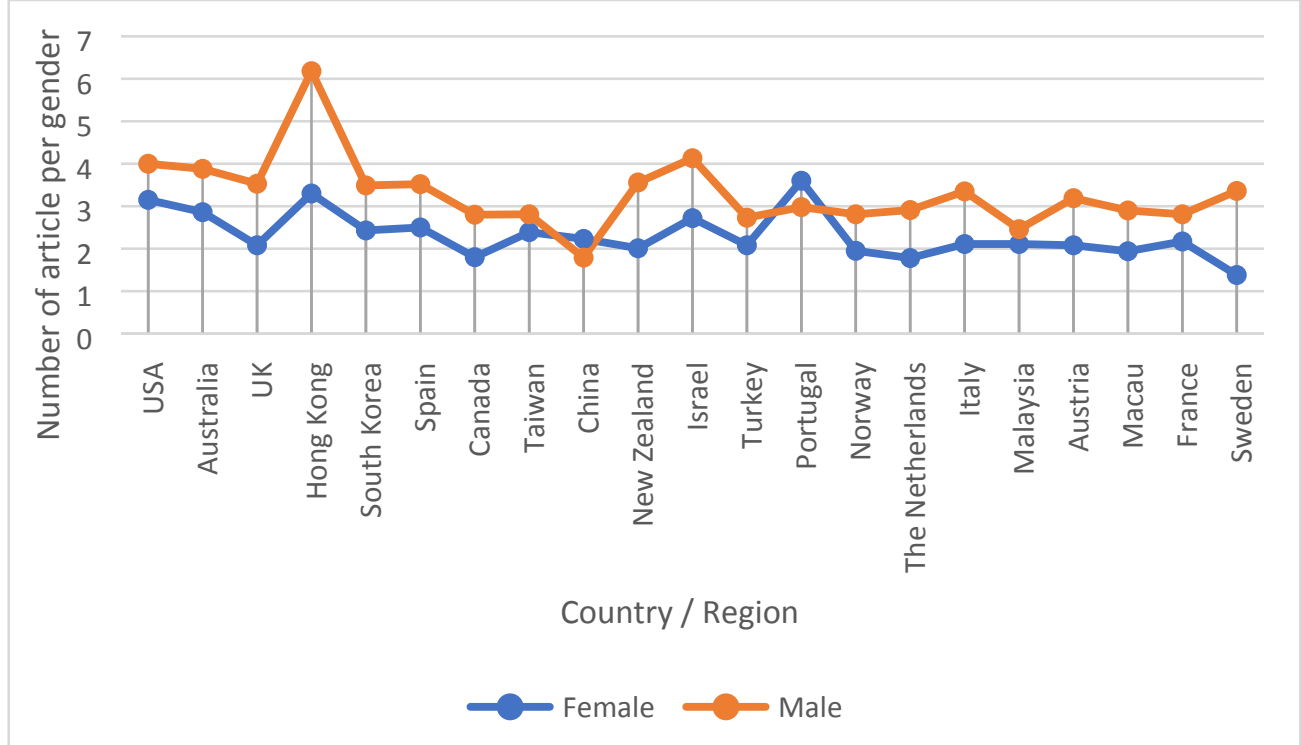

B- Gender Productivity

Figure 3. Gender representations and productivity by country/region. 


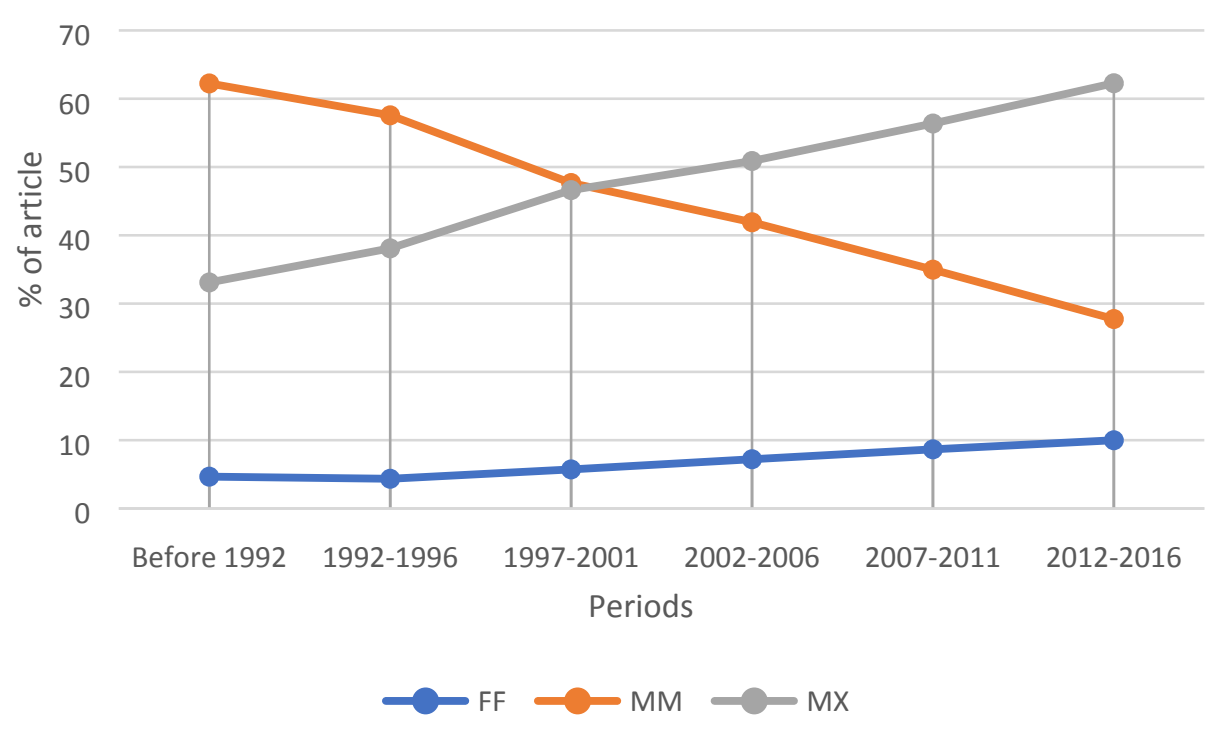

A- Type of collaboration by gender

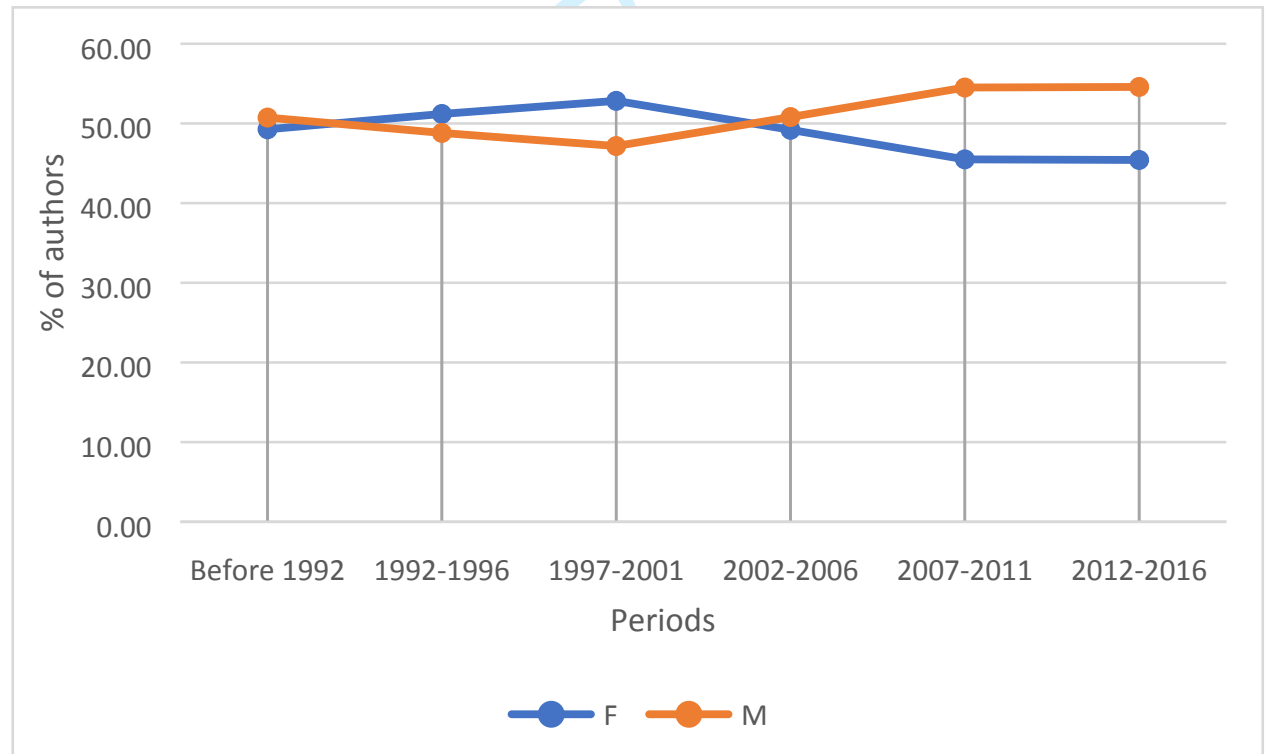

B- Author gender in mixed collaborations

\section{Figure 4. The gender composition of collaborations.}




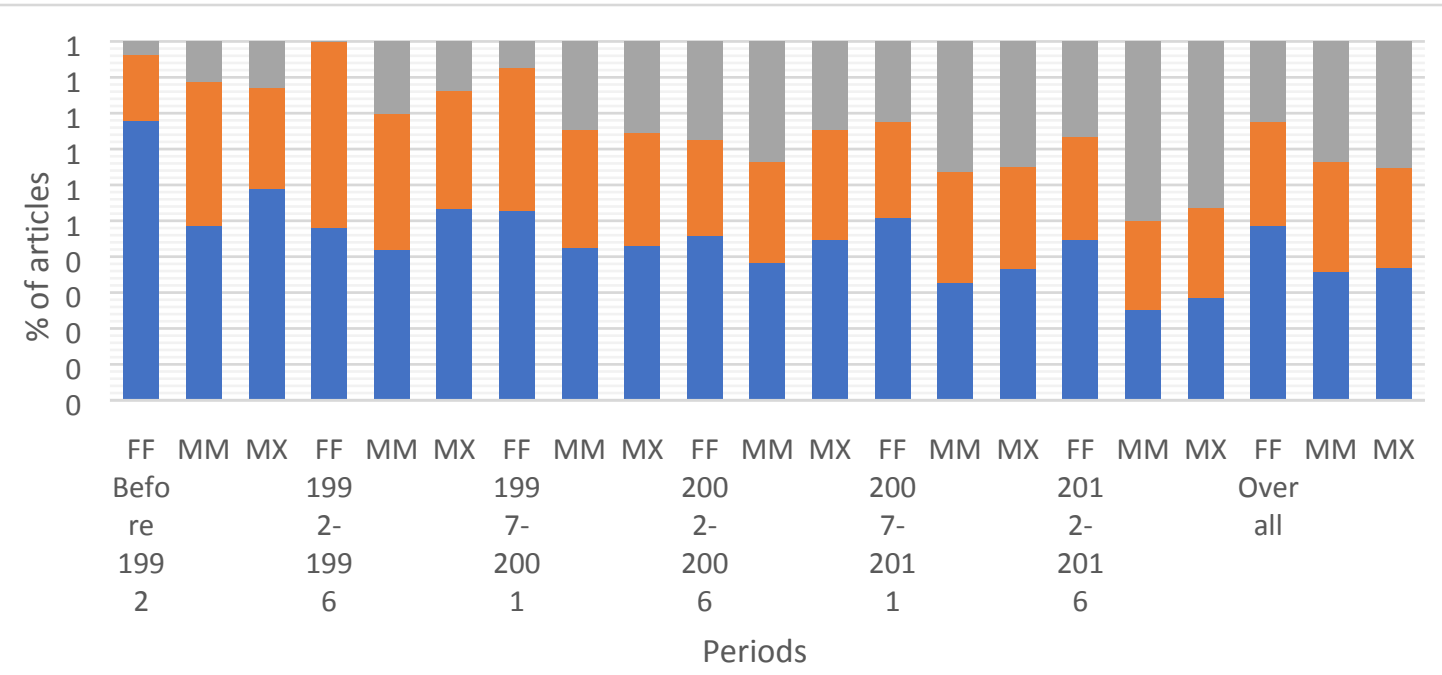

Two or more authors from one institution and from one country

Two or more authors from at least two different institutions from one country

Two or more authors from two or more institutions and two or more countries

\section{Figure 5. Gender composition in international collaborative articles.}




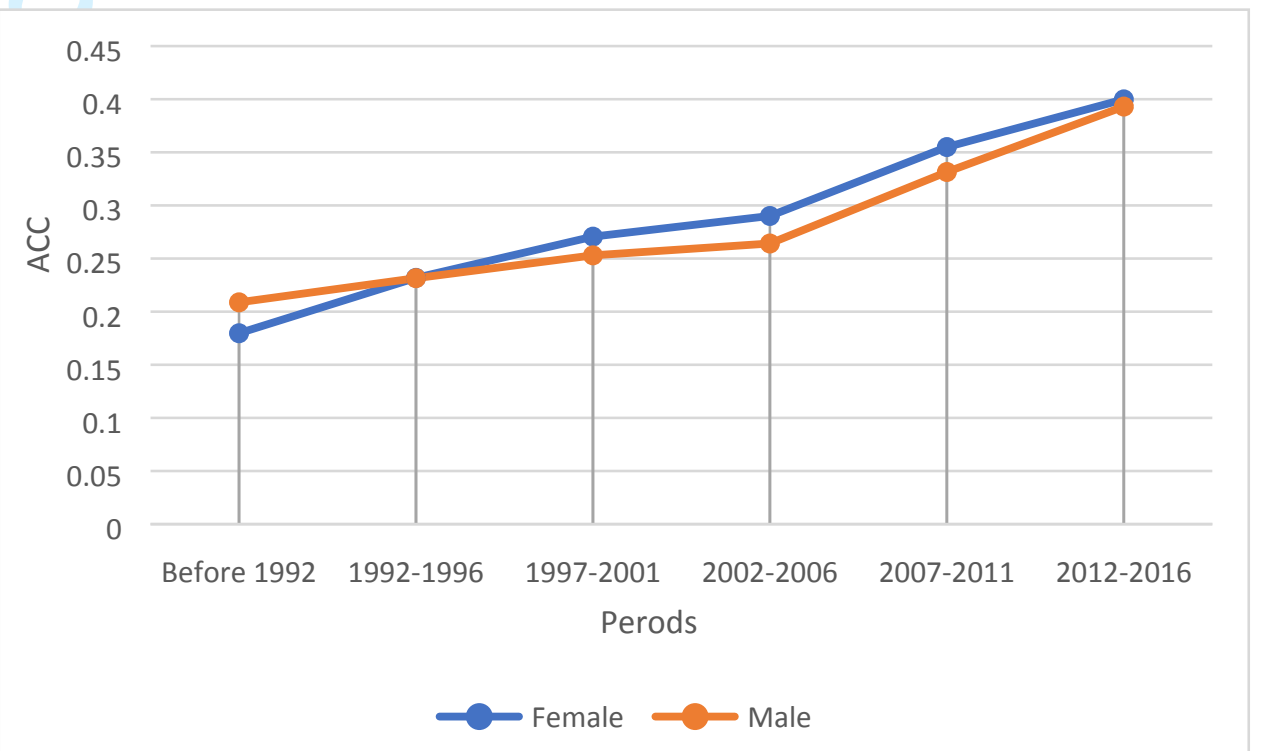

Figure 6. Average clustering coefficient (ACC) of gender by period. 


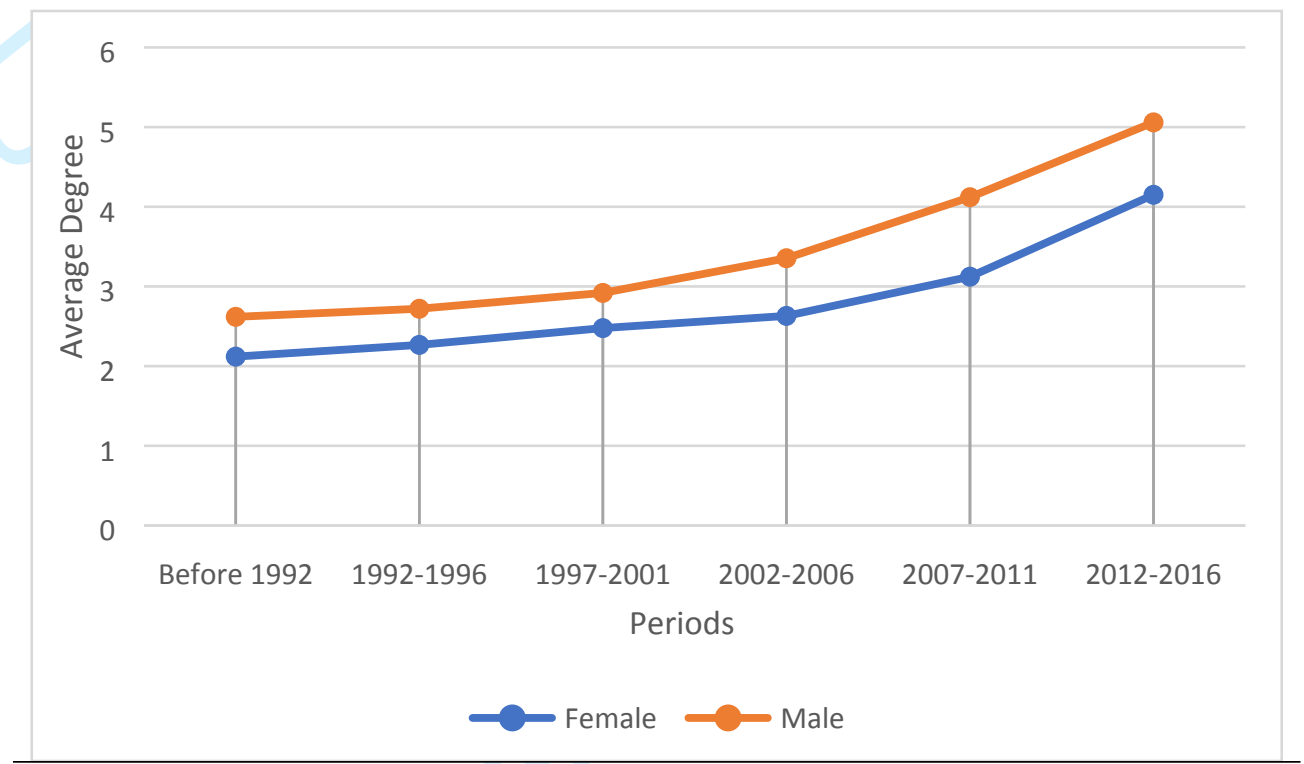

Figure 7. Average degree centrality of gender by period. 


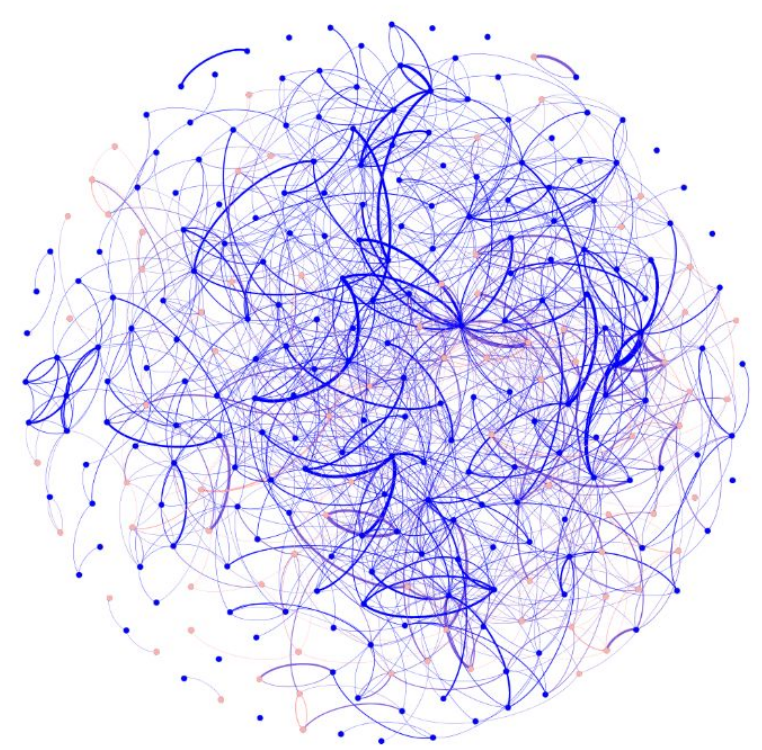

Degree: at least 20

Authors: 290

Female-78

Male-212

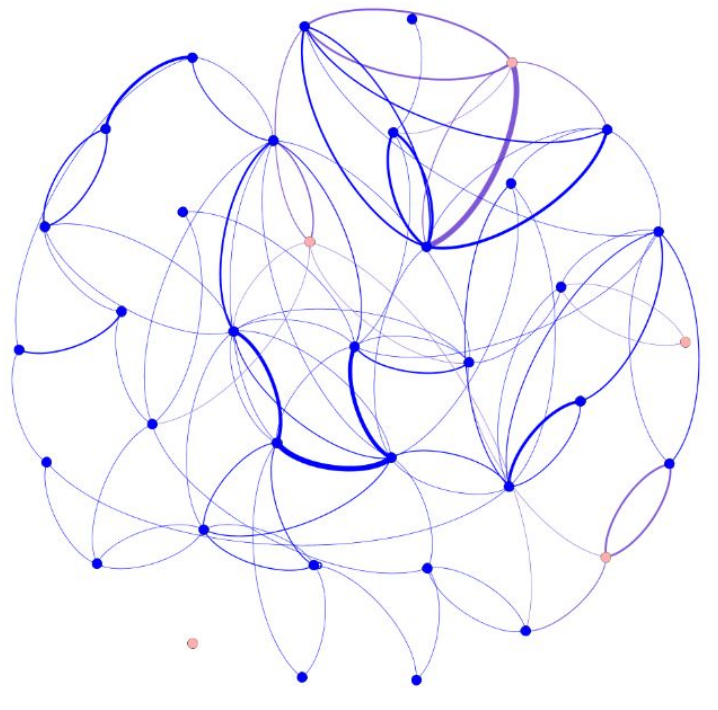

Degree: at least 50

Authors: 37

Female-5

Male-32

\section{Figure 8. Co-authorship network of authors (1965-2016) based on degree centrality}

